\title{
UMA TRADUÇÃO PARA O “AGATHOS” GREGO
}

\author{
Jorge Luiz Lima de Souza
}

\section{RESUMO:}

Guiado pela investigação lógica e buscando sistematicamente denunciar e desfazer anacronismos, este discreto estudo questiona a tradução mais recorrente do verbete grego agathos, isto é, "Bom/Bem", e, confirmando sua limitação e, em alguns casos, sua total inaplicabilidade, propõe "sentir-se bem" como tradução correta. De fato, uma vez testada a nova semântica nos textos aqui estudados, confirmou-se ser ela a mais apropriada e verdadeira.

PALAVRAS-CHAVE: Agathos. Tradução. Bom/Bem.

\section{ABSTRACT:}

Guided by logical investigation and systematically seeking to denounce and undo anachronisms, this discreet study questions the most recurring translation of the Greek word agathos, that is, "Good/Goodness", and confirming its limitation and, in some cases, its total inapplicability, proposes "feel good" as the correct translation. In fact, once the new semantics has been tested in the texts studied here, it has been confirmed that it is the most appropriate and true.

KEYWORDS: Agathos. Translation. Good/Goodness.

Há mais de 50 anos, no ensaio introdutório de sua corajosíssima tradução de 8 textos platônicos ${ }^{1}$, W. R. M. Lamb (1964, p. xi) nos esclarecia, sugerido, supomos, mais por interpretação própria do que por uma verdade minimamente lógica, que Sócrates criara "uma nova ciência a

\footnotetext{
${ }^{1}$ Charmides, Alcibiades I And II, Hipparchus, The Lovers, Theages, Minos e Epinomis.
} 
partir de uma reconhecida teoria das 'ideias' ou 'formas"” oriunda da "reflexão sobre a qualidade atribuida quando dizemos 'esse homem é bom" - o bom aqui referido é agathos. E prossegue o tradutor declarando placidamente algo, no nosso entender, não menos que inverossímil: dizer que alguém é bom, seria, segundo Sócrates (ou melhor, segundo imputa the Lamb), "postular alguma realidade segura por trás de fugazes objetos do sentido"2 (tradução e grifos nossos).

Repete-se, assim, na formulação da tradução de agathos o que já ressaltáramos na seção anterior de nosso estudo ${ }^{3}$, isto é, bem como se acata uma só beleza jazendo externamente, tal se fora uma entidade autônoma, também o Bom ou o Bem, visto que os sentidos são falíveis, habitam fora do observador e somente após detida deliberação se encontrarão aptos para serem reconhecidos. Para confrontação, tratemos do que nos narra o Timeu platônico, já que consta também ali o mesmo agathos mencionado por Lamb. Nesse diálogo, lemos uma tentativa de elucidar a geração do mundo (kosmos); tal será a teoria: duas seriam as possibilidades em que se baseou o criador — ou o artífice (dêmiourgos) — para originar todas as coisas, a saber, no que é eterno, cuja assimilação se dá por meio da razão e do pensamento, ou no que devém, sendo este somente apreendido pela opinião (doxa) oriunda da percepção sensível (aisthêsis), declaradamente oposta à racionalidade. Após deliberar com o auxílio da lógica, é por esta segunda alternativa que o personagem de Platão opta, com base na coerência das seguintes palavras: “[...] se o mundo é belo e o demiurgo é bom [agathos], é evidente que pôs os olhos no que é eterno [para criar o mundo, que não o é]" (Platão, Timeu, 29a.) ${ }^{4}$.

Pode-se, por um lado, assinalar que a conclusão aí levada a termo por Timeu se origina num raciocínio inteiramente inapreensível uma vez

\footnotetext{
2 "The point is that he [Sócrates] made a new science out of a recognized theory of "ideas" or "forms", which had come of reflecting on the quality predicated when we say "this man is good", and which postulates some sure reality behind the fleeting objects of sense."

${ }^{3}$ Esta análise é parte de uma pesquisa mais ampla, cuja tratativa esquadrinhou e contestou também as traduções dos verbetes gregos kalos e kalokagathia.

${ }^{4} \mathrm{Na}$ antiquíssima versão de Archer-Hind, de 1888: "If now this universe is fair and its Artificer good, it is plain that he looked to the eternal".
} 
submetido a parâmetros modernos. Acreditamos de modo patente, contudo, que nosso problema com essa frase decorre de algo ainda mais danoso. A bem da verdade, não nos seria impossível aplicar nossa sensibilidade atual ao que foi dito e enfim compreendê-lo; acontece que é o nosso próprio entendimento - em que a tradução e a interpretação de conceitos gregos seguramente interferiram durante milênios —, e não nossa percepção sensível, que se encontram "interditados". Experimentemos contrapor a lógica de Timeu (de sua tradução, referimo-nos) à frase de Umberto Eco na introdução ao seu gigantesco inventário de belezas, para assim melhor discernirmos discrepâncias concernentes a (e a obstruções de) sentido: “[...] em diversas épocas históricas criou-se um laço estreito entre o Belo e o Bom” (2010. p. 8.). Explícito está, embora ele não o restrinja, que se achavam entre os teorizadores do Belo, e não no público ordinário, aqueles que ataram o tal laço. Logo adiante, Eco derrubará sua colocação não por desqualificá-la como inespecífica ou sobremaneira anacrônica, mas em favorecimento de novas teorizações ${ }^{5}$ a respeito da natureza do Bem, considerada por ele atrelada ao desejo e à posse, ações que diferenciariam, bem possivelmente antagonizando, as essências tanto do Belo quanto do Bom.

Será que podemos concordar com tais informações? Melhor: nossas mais costumeiras e arraigadas noções do Bem sobreviverão, resistindo, a uma bateria de perguntas e conjecturas? Testemos. A começar pela tradução da frase de Timeu, precisamos responder: como ele soube que o demiurgo era bom? Qual relação há, afinal, entre a beleza do mundo e a bondade do criador? Não se explicaria aí anacronicamente? ${ }^{6}$ Ora, deus — o nosso Deus cristão - criou o mundo e viu que "era bom" (Gênesis 1:31), isto é, bem feito, ajustado, sem problemas nem defeitos; logo, tal se o pode estender ao demiurgo.

\footnotetext{
${ }^{5}$ Como se percebe, mesmo num catálogo de belezas como o de Eco cabe teorização, apesar de superficial e fingidamente despretensiosa.

${ }^{6}$ Nas palavras de B. Jowett: “[...] ao traduzir Platão, seria igualmente anacronismo introduzir-lhe o sentimento e o espírito das escrituras judias ou cristãs ou termos técnicos da filosofia hegeliana ou darwiniana." (1891, p. xxiii, tradução nossa) Advertência que ele dá e, desgraçadamente, não segue, como notaremos um pouco mais adiante.
} 
Todavia, se por um lado bem o depreenderíamos se acreditássemos que Timeu ouviu o canto da Teogonia hesiódica, o mesmo, a menos se com deboche, não se aplicaria a uma provável leitura sua do gênesis bíblico. Além do mais, ver em algo criado um perfeito funcionamento não mantém qualquer mínimo vínculo com a bondade - o deus cristão é considerado bom, frise-se, primeiro porque ele assim o declara e, depois, para diferenciálo do diabo, que é mau. O demiurgo, no entanto, e isso nos intriga, é Bom estritamente de acordo com a lógica dialética de Timeu (e, por conseguinte, com a de Platão, o autor, e a de Sócrates, que assiste à fala sem retificá-la). Outras questões: lemos também em 29e que "Ele [o demiurgo] era bom [agathos], e no que é bom [agathos] jamais nasce inveja de qualquer espécie."”. Ora, não invejar é peculiar ao que é Bom?

Há já liberdade para arrazoarmos no seguinte sentido: não seria mais cristão do que platônico o conceito de bondade lido (traduzido, convém esclarecer) em ambos os trechos? Mas em quais bases sustentamos essa crítica? Em vez de responder e encerrar precocemente nossas conjecturas, examinemos antes outra passagem do próprio Platão, desta vez o diálogo Lisis, em que agathos é uma vez mais traduzido como Bom/Bem. Por razão de antiguidade, decidimos não usar a versão de Lamb desse diálogo, mas a de B. Jowett, cujos trabalhos antecedem os daquele em mais de cinquenta anos. Essa escolha nos exibirá um panorama histórico da semântica anacrônica embutida nesse termo.

De acordo com o que escreve Platão, enquanto apura o conceito de amizade $(\text { filia })^{8}$ inquirindo Lísis e Menexeno, Sócrates estabelece uma diferenciação bastante relevante. Ele descobre que a filia tenciona a uma finalidade distinta da pessoa do amigo, haja vista, muitas vezes, valorizarmos algo não em si, mas com vistas a coisas que aquele algo nos proporciona; tal assim sucederia à amizade, isto é, sem saber, miramos no amigo para alvejar outra coisa. Entra aí, no 220b, o trecho de que nos aproveitaremos: "Podemos, então, inferir", são palavras (traduzidas) de

\footnotetext{
7 "He was good, and in none that is good can there arise jealousy of aught at any time."

8 Também contra a tradução deste termo como "amizade" planejamos expor em oportunidade futura diversas contestações.
} 
Sócrates, "que o bem [agathos] é o amigo? [...] E o bem [agathos] é amado por causa do mal $\left[\operatorname{kakos}^{9}\right]^{\prime 10}$. Seja contextualizada, referimo-nos à leitura no corpo completo do diálogo e não por frases salteadas, seja parcial, a assimilação plena desse arremate socrático faz-se impraticável.

É conveniente relembrar que a descrição ali é de um diálogo, o qual, facilitado pelo método de Sócrates, acolheria toda e qualquer contraargumentação — rebate que não se dá naquele caso. Lógico é, por conseguinte, que os interlocutores, e não nós e o tradutor, conheciam a fundo o sentido do agathos aí empregado. Bem poderíamos conjecturar, como Lamb ${ }^{11}$, que tanto se adiantara a filosofia grega na temática da bondade - concernente a certo Bem original externo, real em si — que se achava já em vias de distingui-lo, fosse qual fosse o disfarce por ele utilizado. Todavia, se alinharmos por aí nossa estimativa de compreensão, colidiremos, como Lamb, não apenas com os textos platônicos, e com a cultura em que eles foram produzidos, mas com a própria realidade prática.

Imaginemos um homem a quem consideramos bom após assistir-lhe sendo caridoso. Nada nos habilita para atestarmos objetivamente sua bondade. Isto posto, imaginemos flagrar o mesmo indivíduo matando uma pessoa. Ora, imediatamente afirmaremos que ele não é bom, embora suspeitemos de que seu estado pode não ser permanente, afinal, bem como foi o ato caridoso que nos assegurou sua bondade, será o ato de matar (em si) que julgaremos não bom, correlacionando, por lógica, o mesmo juízo àquele que o pratica; contudo — somos obrigados a reconhecer - , apenas enquanto ele o pratica. Nunca poderemos avaliar de maneira segura se, antes, quando testemunhamos esse futuro assassino num ato de caridade, ele

\footnotetext{
${ }^{9}$ Convém a este estudo familiarizar nosso leitor com uma das derivações dessa palavra. De kakos, aí traduzida como "mal", se ramificará kakophonia, em português "cacofonia", termo para o qual, não sem um excelente e fortuito repúdio ao anacronismo, se destinará o preciso sentido de som (phoné) desagradável (kakos) [de se ouvir]. Percebam, tal lhes será importantíssimo, que a parte desagradável (neste caso, do som) não mantém nenhuma relação, ao contrário, com a maldade, sendo-lhe inclusive "irrelacionável”; ocorre tão somente, aí sim, de o ouvinte sentir-se mal ao escutar a tal kakophonia. A partir de agora, não nos afastemos em momento algum dessa reflexão.

10 "May we then infer that the good is the friend[?] [...] And the good is loved for the sake of the evil[?]"

11 cf. nota 2 .
} 
fingia ser bom ou se o era honestamente ${ }^{12}$. E até onde nossas pesquisas nos asseguram, não nos chega notícia de que Platão tenha formulado com o auxílio de Sócrates uma técnica indefraudável com auxílio da qual se pudesse legitimar a bondade de qualquer pessoa, sem que para tal necessitemos de acreditar em suas ações - e ainda assim com considerável margem de erros. Há, porém, o que especular aqui: não miraria a pesquisa socrática justamente esse projeto, isto é, tangenciar o mais possível o terreno genuíno de bondade em que habitaria a ação boa do homem bom, com o intuito de revelar o Bem Maior incluído nos bens ordinários? Feliz ou infelizmente, tais divagações serão desqualificadas mais à frente.

A propósito de agir, seja bem ou mal - e logo retornaremos, para arrematá-las, às conjecturas até aqui abertas —, sairemos por ora de Platão com vistas a estudar do que trata Isócrates concernente à ação. Esse ilustre orador ateniense começa sua carta a Arquidamo, rei de Esparta, garantindo que as instruções (em grego, stratêgiai) que lhe passará sobre campanhas militares, se ele as seguir, irão convertê-lo em "author of great benefits [agathos], not only to your own state, but also to all the Greek world" (Letter IX, 434.1). Adiante, no 434.2, Isócrates admite saber que com esse assunto não é fácil lidar, haja vista "praise [...] virtues" ser simples como brincadeira de criança, ao passo que "discover actions [praxis] which are noble [kalas; leia-se 'ações belas'], great, and advantageous is difficult and given to few men". A raridade de belas praxis aí maldita pelo autor da carta por si só já configura uma primeira investida contra as divagações a respeito de uma improvável teoria socrática visando à investigação de um Bem, referenciada apenas pelo agir; ora, se fosse por intermédio da ação (bela) que se reconheceria um (homem) bom, para daí buscar o Bem supremo, alcançaríamos, então, os mais pífios resultados, pois, conforme reclama Isócrates, enquanto excedia a bajulação aos poderosos, rareava, por ausência delas, o enaltecimento das melhores ações. Tal sistema - tivesse o

\footnotetext{
${ }^{12}$ Aliás, especular se o praticante de um ato bondoso está verdadeiramente sendo bom nos parece mais fruto de parcialidade do que de ceticismo, haja vista o mesmo não se aplicar ao seu contrário: alguém cogitaria que o praticante de um ato de maldade o pratica bondosamente? Ou que aquele que protagoniza um ato de fúria o faça sem estar furioso?
} 
examinador a sorte de encontrar ao menos uma cobaia - comportaria, ainda assim, tantas brechas para erros que seria admirável não haver nenhuma contestação as frustrando de imediato nas dialéticas descritas por Platão. Isso nos sugere que a busca por esse Bom/Bem poderia não ser a intenção ali, senão a de um objeto completamente diverso contido no verbete agathos. Para assegurarmos nossa posição, retornemos ao Lísis.

Logo após asseverar, segundo as traduções, que "o bem [agathos] é o amigo [...]" e que "o bem [agathos] é amado por causa do mal [kakos]" (220b), Sócrates progride seu raciocínio recapitulando suas exposições até o momento, entre as quais consta uma de suas teses mais conhecidas, isto é, a dos três estados do ser humano ou a teoria da inclinação. Em 216d, ele já orientara o diálogo rumo a uma tríplice elaboração, segundo a qual haveria “[...] o bem [agathos], o mal [kakos] e o que não é nem bom [agathos] nem mau [kakos]"13; seria esse estado intermediário — nem bem, nem mal que faria o humano se inclinar para um ou outro lado, embora, ainda segundo as traduções, ele logo tendesse para o bem (por mais cristão que isso venha a nos parecer). Esse trio, da forma como a tradução sugere, não é concebível, pois questões lógicas imediatamente emergem: o que é o bem? O que é o mal? Por que o homem, em estado intermediário, inclinar-se-ia para o bem? É razoável já tratar do meio-termo quando nem mesmo os termos inteiros foram acertados? E ainda que exemplifiquemos anacronicamente, a inexatidão persiste; no caso de um assassino, quando ele está sendo mau? Quando mata. E quando está sendo bom? Quando não mata. Mas, afinal, em que instante ele não é uma coisa nem outra? Se pensarmos especialmente sob o ponto de vista das vítimas, não haverá bondade mais perfeita a ser praticada por um assassino do que não matar, resistindo com perseverança e vigilância ao impulso odioso. Ora, se assim for, cada segundo dos seus dias de regeneração se converterá em constante bondade, não restando tempo algum para o estado intermediário; a força positiva, boa, produzida na contenção do vício violento não permitirá que ele mate, tanto quanto nunca autorizará que ele permaneça um momento

\footnotetext{
13 "[...] the good, the bad, and that which is neither good nor bad."
} 
sequer neutro ao bem de que necessita ininterruptamente para sublimar sua própria maldade.

Portanto, não só discordamos da tradução desse agathos, como mesmo da ausência de lógica que ele imputa aos diálogos platônicos, os quais, aliás, como reiterado, se encontram povoados de interlocutores concordando tão prontamente tanto com as premissas quanto com seus arremates; isso nos sugere que a teoria platônica das "ideias" guardava em seu fundamento uma lógica absoluta, mais: apreensível, alicerçada em percepções gerais e invocada para hipóteses de origem. Não cremos que Platão planejava fabricar e inventariar ideias mais do que cogitar gênesis e propósitos para realidades já comuns a todos, mas para cujo valor, justamente por se tratar de sensibilidades experimentadas por todos e qualquer um desde sempre, eles não davam o crédito devido nem questionavam com mais curiosidade.

Tentemos, então, a partir de agora primeiro concordar com uma verdade imbatível, para, aí sim, meditar sobre ela. Suponhamos, para testálo, que o agathos ali escrito por Platão não fosse o nosso Bem ou Bom, mas sentir-se bem; cogitemos se ele, com base na semântica real desse termo, ao referir-se ao homem bom, aludisse não a um Bem externo, a um só tempo personificado e desumanizado, transcendente, mas, em lugar dele, à satisfação sensorial experimentada por todos os indivíduos do mundo, em todas as épocas, pelo menos por uma vez em suas vidas, e à qual todos constantemente aspiram, sempre com presciência de realização; sensação nunca aprendida, embora todos usufruam dela com invejável autonomia desde o nascimento - um axioma imbatível. Ora, se assim for, encontramonos, por fim, diante de uma primeiríssima certeza. Da mesma forma como jamais nos capacitaremos plenamente para determinar se um homem é bom, em decorrência da inexatidão das variáveis que adotaremos como objetos para a averiguação, o oposto disso poderíamos declarar: a satisfação sensorial associada ao sentir-se bem não nos impede, ao contrário, de certificar-nos do que seja esse sentimento. 
Como alcançamos tal discernimento? Por que, ao meditarmos a respeito do porquê de nos sentirmos bem, somos forçados a subscrever a mais divulgada das peculiaridades da personalidade socrática, o qual "professava não possuir nenhum conhecimento, exceto o de saber-se ignorante" (LAMB, 1964, p. xi-xii, tradução nossa) ${ }^{\mathbf{1 4}}$ ? Em que instante se cristalizou a naturalidade com que nós e todas as pessoas do mundo sabemos, sem contudo efetivamente sabermos, que, em dados momentos, nos sentimos bem? Essa "ideia", para cuja origem a teoria platônica apontaria, - por jazer assentada, misteriosamente proliferada e por ser, aí sim, infalível — nos possibilita um segundo passo: investigá-la. É o que Platão e, depois, Aristóteles, seu aluno, farão.

Recapitulemos e refaçamos as passagens até aqui duvidosas, empregando essa nova semântica de agathos, a começar pelos três estados da teoria socrática. Ora, tal como sabemos quando nos sentimos bem, o mesmo podemos aplicar ao "sentir-se mal"; assim, um homem, ao caminhar na rua, pode sentir-se bem ao deparar-se com determinada cena e, em seguida, ao virar uma esquina, sentir-se mal por presenciar outro acontecimento; contudo, horas depois, quando chega à sua casa e se senta no sofá, aí sim, ele poderá não se sentir nem bem, nem mal — será o estado intermediário. No entanto, o tal homem sabe que, em dado instante, poderá topar com uma cena que lhe desperte mais uma vez o sentir-se bem, tanto quanto testemunhar algo que, ao contrário, o faça sentir-se mal. De posse desse saber, ele se acha, de fato, inclinado a sentir-se bem, porque já experimentou o desagradável ao sentir-se mal e urge por fugir dessa sensação. Todo homem está inclinado a sentir-se bem (agathos), e não mal. Mas - se não chegamos ainda ao conhecimento do porquê dessa satisfação sensorial - convém ao menos nos perguntar: o que produz verdadeiramente esse sentimento? O amor? A amizade? O Belo (independente de quem seja esse Belo)? Qual será seu inspirador natural?

Nenhuma resposta, no entanto, é assim, simples. Em Lísis 221a, Sócrates conjectura sobre o desaparecimento do "mal", de acordo com a

\footnotetext{
14 “[...] he [Sócrates] professed to have no knowledge himself, except so far as to know that he was ignorant."
}

Filos. e Educ., Campinas, SP, v.11, n.2, p.290-301, maio/ago. 2019 - ISSN 1984-9605 
antiga tradução. Cogitado esse cenário, ele o exemplifica, questionando-se como seria sentir fome ou sede num mundo sem o "mal". Eis aí a profundidade da perturbação que a ausência de lógica nos causa. Pelo que se inferia no que vinha sendo traduzido, o pensamento socrático considerava um homem mau caso ele sentisse sede e, por oposição lógica, bom caso ele bebesse água! Novamente, testemos a semântica mais adequada, isto é, antônima a sentir-se bem. Imaginemo-nos com muita sede. Como nos sentimos? Bem ou mal? Agora, imaginemos o momento em que saciamos essa sede. É inegável que nos sentimos bem. O que aconteceria, porém, se o sentir-se mal desaparecesse do mundo, tal como Sócrates pondera? A sede continuaria existindo, ele ressalva, no entanto, não teríamos a sensação desagradável que nos avisa que temos de beber água. Mais uma vez, a questão se complica: o filósofo nos lembra que num eventual sumiço do sentir-se mal (por ter sede ou fome), também desaparecia o sentir-se bem por saciá-las. Recomeça, a partir desse empecilho, mais uma investigação.

Voltemos, finalmente, ao Timeu e ao seu demiurgo, os quais abandonáramos logo no início por não compreender-lhe a tradução. Soltamos diversas perguntas provocadas pelas frases "[...] se o mundo é belo e o demiurgo é bom [agathos], é evidente que pôs os olhos no que é eterno [para criar o mundo, que não o é]" (29a) e "Ele [o demiurgo] era bom [agathos], e no que é bom [agathos] jamais nasce inveja de qualquer espécie" (29e). Embora não restem empecilhos para a compreensão da primeira frase - o demiurgo se sente bem ao criar o mundo —, se possível, orientamos, para finalizar qualquer outro questionamento, a leitura completa desta pesquisa ${ }^{15}$, em que se investigou a estreita relação entre o Belo (nesse caso, o mundo) e o sentir-se bem (nesse outro caso, o demiurgo, que o criou); quanto à segunda frase, acreditamos que o sentido se tornou óbvio, consoante com a lógica interna do discurso: aquele que por qualquer causa está se sentido bem, pouquíssima ou nenhuma necessidade terá de invejar seja quem for, estando sua disposição inclinada, como é comum, unicamente para esse sentir-se bem.

\footnotetext{
${ }^{15}$ cf. nota 3.
} 
Resta ainda, apenas por burocracia, ajustar os sentidos de dois outros conteúdos aqui citados. São eles:

O Lísis: "[Sócrates:] Podemos, então, inferir que o bem [agathos] é o amigo? [...] E o bem [agathos] é amado por causa do mal [kakos]" (220b), em que se deve ler que "é o amigo que nos faz sentir bem"; afinal, a lógica e a experiência não nos dão notícia de que a cumplicidade de uma amizade saudável tenha provocado náuseas ou qualquer coisa do tipo. E, na segunda parte, "sentir-se bem é amado por causa do sentir-se mal" (220b); como demonstrado, nada nos faz apreciar e louvar mais a satisfação sensorial com que o sentir-se bem nos brinda do que nossa urgência para fugir de tudo o que, depois de experienciarmos, nos fez sentir mal.

Por fim, Isócrates em carta para o rei Arquidamo: se este seguir suas instruções, tornar-se-á "author of great benefits [agathos], not only to your own state, but also to all the Greek world" (Letter IX, 434.1). Dar meios a um rei de executar a tarefa impossível de fazer todo o mundo grego sentir-se bem é, como bem reconhecera Isócrates, bastante mais difícil do que copiar a tantos outros e simplesmente bajular suas virtudes.

Terminamos, assim, apenas por constatar o que os indícios nos textos gregos já nos insinuavam fortemente: era o interior do homem, sua percepção sensível, que lhe fornecia suas referências mais substanciais e era aí exclusivamente, dentro dele, de sua própria alma (psiquê), que ele buscava a verdadeira epistemologia humana - uma ética; ou seja, assim como já aconselhara devidamente o oráculo de Delfos: Conhece-te a ti mesmo...

\section{REFERÊNCIAS}

A Bíblia Sagrada. Tradução de João Ferreira Almeida. L.C.C. Publicações eletrônicas, 2006.

ECO, Umberto. História da beleza. Tradução de Eliana Aguiar. $1^{\mathrm{a}}$ ed. Rio de Janeiro: Record, 2010.

Filos. e Educ., Campinas, SP, v.11, n.2, p.290-301, maio/ago. 2019 - ISSN 1984-9605 
ISOCRATES. Isocrates III Orations-Letters. With an english translation by LaRue Van Hook. $1^{\text {a }}$ ed. Cambridge, MA: Harvard University Press, 1945.

PLATÃO. Timeu-Crítias. Tradução de Rodolfo Lopes. $1^{\mathrm{a}}$ ed. Coimbra: Centro de Estudos Clássicos e Humanísticos, 2011.

PLATO. Charmides, Alcibiades I e II, Hipparchus, The Lovers, Minos, Epinomis. With an english translation by W. R. M. Lamb. $3^{\text {a }}$ ed. Massachusetts: Harvard University Press, 1964.

PLATO. Charmides, Lysis, Laches, Protagoras, Euthidemus, Cratylus, Phaedrus, Ion, Symposium. Translated into english by B. Jowett. $3^{\text {a }}$ ed. London: Oxford University Press, 1891.

PLATO. Timaeus. Tradução de R. D. Archer-Hind. $\quad 1^{\text {a }} \quad$ ed. $\quad$ Londres: Macmillan and Co., 1888.

Submetido em: $28 / 07 / 2019$

Aceito em: 01/02/2020

Publicado em: 27/03/2020 